\title{
UN INFORME PARA UNA ESTRATEGIA DE DESARROLLO REGIONAL ALTERNATIVO PARA ANDALUCIA
}

Francisco ALBURQUERQUE*

\begin{abstract}
"En muchos aspectos el desarrollo regional es un conflicto de intereses entre un centro poderoso y una periferia que debe reunir todas sus fuerzas para una lucha desigual. Solo la integración de las capacidades locales y un claro sentido de identidad regional pueden proporcionar las condiciones para el éxito".
\end{abstract}

Eduardo NEIRA:

"Políticas de desarrollo urbano y regional en América Latina", Buenos Aires, Ed. SIAP, 1972.

\section{PROLOGO}

Este trabajo fue realizado por mí, durante mi reciente estancia de seis meses en la sede de la Comisión Económica de las Naciones Unidas para América Latina y el Caribe (CEPAL), como asistente al XXVII Curso Internacional del Instituto Latinoamericano de Planificación Económica y Social (ILPES) sobre "Desarrollo, Planificación y Políticas Públicas", becado por el Instituto de Cooperación Iberoamericana, del Ministerio de Asuntos Exteriores del Estado Español.

(*) Colaborador científico del C.S.I.C. en la Escuela de Estudios Hispanoamericanos de Sevilla. Director de la Unidad de Investigación sobre Economía y Sociedad en la América Contemporánea. 
Constituye un ensayo, ciertamente simulado - aunque, como podrá comprobarse, con notable capacidad operativa para encarar los problemas del país andaluz- ${ }^{1}$, que intenta presentar las líneas básicas de actuación que podría llevar a cabo una Consejería de Desarrollo Regional de Andalucía, aún hoy inexistente, al efectuarse el planteamiento de la política regional del desarrollo según una concepción de "arriba hacia abajo", y no como un diseño llevado a cabo de "abajo hacia arriba", por los propios actores y movimientos sociales y económicos regionales.

Dada la actual composición política en el Parlamento andaluz, con mayoría PSOE, y dado el carácter del proyecto político y económico que a nivel estatal se sustenta por parte de tal grupo social hegemónico (y que condiciona poderosa y negativamente el desarrollo regional de Andalucía), el que suscribe estas líneas sería ciertamente ingénuo si aspirase a algo más que a exponer públicamente la propia estrategia alternativa de desarrollo regional para Andalucía, en un contexto de desarrollo solidario de la construcción económica, social, política y cultural, del Estado de las Autonomías en España.

Al menos que no pueda decirse que tal estrategia no existe, siquiera sea en el nivel de la exposición teórica de la misma.

Debe entenderse pues que el presente ensayo es esencialmente una propuesta que creo podría constituir un modesto referente de conexión para las ofertas políticas y sociales que se sitúan en el ámbito de la izquierda (tanto tradicional como alternativa), y del nacionalismo andaluz.

Los avances electorales de la izquierda y de los nacionalistas en Andalucía (o en cualquier otra "periferia" del sistema capitalista), solo podrán multiplicarse, y alcanzar así a realizar un proyecto capaz de cambiar la economía y la sociedad en nuestro país andaluz - y no solo de presentarlo como "alternativo" o como frustrante "oposición" testimonial-, cuando sus principales representantes y dirigentes encaren el desafío que implica el hecho - para mí meridianamente evidente- de que, hoy por hoy, un proyecto alternativo de desarrollo regional (o nacional) para Andalucía es, al mismo tiempo, un proyecto nacionalista y de izquierda.

1. En este ensayo utilizo indistintamente los términos PAIS, NACION o REGION para referirme a ANDALUCIA, reservando el término ESTADO ESPAÑOL o ESPAÑA para aludir al conjunto plurinacional del actual Estado de las Autonomías, sancionado por la nueva Constitución democrática. 
En mi opinión, todo el tiempo que se demore la constitución de una unidad de acción (sin renunciar desde luego a las diferencias entre los distintos grupos de afinidad, que más que dividir deberían enriquecer el proyecto) entre izquierda — tradicional y alternativa - y nacionalistas en Andalucía, prolongará la actual hegemonía de los planteamientos conservadores, dada la dejación que tanto el actual partido en el gobierno autonómico como también en el gobierno del Estado español han efectuado respecto a la problemática regionalista.

El ensayo que aquí se esboza pretende, por tanto, desde una perspectiva de izquierda alternativa y nacionalista (a la que me siento afin ideológica y vitalmente), seguir alentando la movilización social y política reivindicativa, dentro y - sobre todo- fuera del Parlamento andaluz, en todos los lugares donde los denominados "actores sociales" soportan las carencias debidas a la desigual y adversa situación que se conoce en nuestra comunidad autonómica y, por cierto, en las otras comunidades periféricas del Estado español o, en general, de las restantes zonas periféricas de la acumulación a escala mundial del capital.

Tal como sabemos, sin una efectiva participación de la población, con capacidad de organización social regional, cualquier propuesta quedaría únicamente en alegato teórico casi inútil. Al aliento mayor de esa fuerza colectiva están dedicadas estas líneas, y no a otra cosa.

Asímismo, condición indispensable ${ }^{2}$ para poder encarar con algún éxito el problema del desarrollo regional, es la de poseer un adecuado conocimiento científico sobre dicha cuestión, además de darse las condiciones políticas efectivamente interesadas en abordar una estrategia de desarrollo regional.

Como podrá verse, la situación actual respecto al desarrollo del Estado de las Autonomías en España, muestra tan sólo la apariencia de una descentralización a ese nivel (lo que no se extiende al terreno económico en ningún caso) mientras el grupo social hegemónico en el gobierno del Estado respalda entusiastamente el proyecto de "modernización" ligado a las nuevas tecnologías, en la suposición de que ello puede conllevar los mayores niveles de crecimiento y desarrollo económico, social y regional. En otras palabras, ello implica que los dirigentes actuales del partido en el gobierno del Estado español y en la Comunidad Autonómica andaluza, comparten una convicción plenamente idílica respecto de los efectos de expansión del crecimiento económico capitalista (lo que, dicho sea de paso, vuelve a confundirse con el desarrollo económico), y todo ello claramente apunta a una considerable falta de conocimiento científico sobre la naturaleza objetiva de la dinámica concentradora del crecimiento económico y su difusión espacial desigual.

2. Sergio BOISIER: "Política económica, organización social y desarrollo regional". Cuadernos del ILPES, número 29. CEPAL/ILPES, Naciones Unidas, Santiago de Chile, 1982, pág. 2. 
Al plantear la necesidad de crear una Consejería de Desarrollo Regional de Andalucía se está insistiendo pues, en el necesario incremento del poder de presión y negociación de nuestra comunidad autónoma ante el gobierno del Estado, con objeto de sustituir la situación actual en la que el partido mayoritario en el gobierno autonómico no solo se muestra incapaz de atender suficientemente las demandas regionales, sino que, en la práctica, se comporta con una subordinación plena a la política económica a nivel de Estado, absolutamente ajena a cualquier proyecto razonable o realista de desarrollo regional para nuestra Comunidad Autónoma, a la que solo parece quedar el acceso a las migajas de las transferencias del FEDER (Fondo Europeo de Desarrollo Regional) o del FSE (Fondo Social Europeo) de la Comunidad Europea.

Estoy profundamente convencido, hoy por hoy, de que la presencia política de fuerzas nacionalistas o regionalistas puede y debe llegar a ser mucho mayor en Andalucía, teniendo —en mi opinión-dichas fuerzas, así como las de la izquierda tradicional y alternativa, el desafío y la responsabilidad de plantear eficazmente desde nuestra Comunidad Autónoma las demandas consiguientes contra el centralismo de Estado, lucha que constituye, tal como señala S. BOISIER ${ }^{3}$ “el problema regional de más evidente dimensión política y la forma más expresiva de presión a favor de las políticas de desarrollo regional".

Así pues, en la medida que la centralización de los procesos decisionales se hace a expensas de las comunidades de base o intermedias, regionales y funcionales, dicha lucha no constituye otra cosa que parte de las exigencias democráticas de reparto o disolución del poder político en el pueblo.

\section{UNA INTERPRETACION DEL PROBLEMA REGIONAL EN ANDALUCIA}

Es bien sabido que el desenvolvimiento de la lógica del mercado provoca fuertes discrepancias en su expansión territorial, con el consiguiente crecimiento desigual interregional. En la terminología de Gunnar MYRDAL 4 , los efectos "de absorción" o retardadores del crecimiento en las regiones menos favorecidas, acaban prevaleciendo sobre los efectos "de difusión", o impulsores del crecimiento.

3. Id., pág. 15.

4. Gunnar MYRDAL: Teoría económica y regiones subdesarrolladas, FCE, México, 4 . $^{2}$ edición, 1978 , pág. 38. 
El conocimiento de los mecanismos objetivos que determinan este crecimiento desigual interregional se hace obligado, por lo tanto, para mejorar nuestro nivel de conocimiento científico acerca del funcionamiento de la realidad socioeconómica, así como para intentar intervenir sobre la misma, mediante determinadas políticas, con el fin de evitar, o disminuir al menos, las consecuencias más negativas de tal crecimiento desigual en el espacio.

El funcionamiento de la economía y la sociedad regional en los Estados plurinacionales, se ve constreñido por la doble limitación que le imponen, por un lado, el contexto del Estado en el que se encuentran integradas, así como la propia dinámica económica del estilo de desarrollo en ese Estado y, por otro, los condicionantes impuestos por el marco y estilo de desarrollo económico, político y cultural transnacional predominante, a nivel internacional.

Históricamente se conformó en Andalucía una estructura económica cuyos rasgos propios internos y su propia organización social local y estructura de clases, no alcanzaron a interiorizar el excedente económico generado que, en gran medida, se ha ido transfiriendo hacia afuera de la región, en beneficio de otras, hoy más desarrolladas.

En este último sentido, el intento de explicar el subdesarrollo económico andaluz en términos de la reproducción de un sistema "centro-periferia" al interior de las fronteras del Estado español, o incluso el de considerar la tesis del "colonialismo interno"6, no parecen nada descabellados ${ }^{7}$.

La dinámica del crecimiento económico capitalista es profundamente desigual, hasta tal punto, y con tanta evidencia empírica, aquí y allá, que sorprende aún la pervivencia de las interpretaciones fantasiosas de la teoría neoclásica de la auto-regulación ${ }^{8}$, que sostiene, como es sabido, la capacidad de regulación automática y equilibradora de los mecanismos del libre mercado.

Por ello, la interpretación conceptual y teórica que subyace a este ensayo se separa completamente de dichas suposiciones irreales, basadas en una falsa concepción del mundo real como "auto-regulado" por mecanismos propios que dicen tender hacia el equilibrio en sus diversas manifestaciones y, concretamente, en cuanto al desarrollo regional armónico y la distribución equitativa del ingreso personal.

5. Véase la aportación de Raul PREBISCH y la CEPAL.

6. Vid. Pablo GONZALEZ CASANOVA: "Sociedad plural, colonialismo interno y desarrollo", en la revista $A M E R I C A$ LATINA, año 6, N. ${ }^{\circ} 3$, julio-septiembre, 1963, Río de Janeiro, Brasil.

7. Vid. mi trabajo: "Andalucía, subdesarrollo y periferia al interior del Estado español", Mimeo. $X X$ VII Curso Internacional ILPES, Mención de Planificación del Desarrollo Regional, Naciones Unidas, Santiago de Chile, 1986.

8. Vid. Stuart HOLLAND: "La competencia desigual y el desequilibrio racional", en Capital vs. the regions, McMillan, Londres, 1976. 
Este inadecuado enfoque teórico, que implica la concepción del desarrollo como un proceso de difusión del "centro hacia bajo", junto al carácter agregado de las teorías en que se fundamenta la formulación de las políticas económicas, han profundizado la "heterogeneidad estructural" de las economías, acentuando los desequilibrios internos y la marginalidad ${ }^{9}$. Ha primado pues la integración funcional de los mercados, desde una perspectiva global, y no como un sistema de regiones.

En este ensayo se parte, pues, de un intento de interpretación que descansa, esencialmente, en el obligado esfuerzo analítico de reflexión sobre las tendencias dinámicas de la propia realidad del desarrollo regional, exigencia ésta de cualquier método de investigación que requiera para sí el estatuto de científico ${ }^{10}$.

Tal exigencia es, como se señaló, indispensable; sobre todo si se prentede - como es el caso de este ensayo sobre la problemática del desarrollo regional en Andalucía—, no únicamente un ejercicio teórico, sino - y sobre todo- una propuesta normativa de actuación.

Es indudable que una de las tendencias principales en la citada dinámica del crecimiento económico capitalista es la que se refiere a la conformación creciente de los procesos de concentración y centralización de capitales, con el consiguiente conjunto de efectos de oligopolización económica, no solo en la esfera de la producción, sino en las restantes fases de la distribución, intercambio, financiación y consumo en el sistema económico.

La propia dinámica intrínsecamente competitiva de la acumulación capitalista conlleva paulatinamente - como es sabido--, a esa oligopolización económica empresarial y sectorial, que se desenvuelve de forma desequilibradora y desigual tanto en el tiempo (dando lugar a un desarrollo cíclico, que combina contradictoriamente fases de auge con otras de recesión, estancamiento y crisis), como en el espacio (originando en este caso un tipo de crecimiento polarizador, tanto al interior de la economía de un país, como en el conjunto de la acumulación a escala mundial del capital).

9. Fernando ORDOÑEZ: "El desarrollo regional en eI contexto de los procesos de ajuste macroeconómicos”. Documento ILPES CPRD-D/96, págs. 10-11.

10. Dicho sea de paso, sin pretender que con ello se llegue a alcanzar de forma definitiva el reflejo de la compleja y variable caracterización de dicha realidad, lo que, de todas formas, sin este recurso, es aún una tarea mucho más difícil. 
Junto a estas tres tendencias citadas en la dinámica realmente existente de la acumulación capitalista (desarrollo oligopólico; desarrollo cíclico y crisis; desarrollo desigual y polarizador), debe añadirse una más, estrechamente vinculada a ellas, pero cuya relevancia es ciertamente destacada en la fase actual del capitalismo maduro: me refiero a la transnacionalización e internacionalización del capital, en sus diversas modalidades de capital-dinero, capital-mercancia y capital productivo $^{11}$.

Cualquier formulación teórica o normativa que no atendiese al análisis de estas tendencias, estaría —en mi opinión - tremendamente dificultada para alcanzar algún nivel de éxito en cualquier propuesta de desarrollo regional. O para decirlo con otras palabras, "la dinámica de la competencia desigual es un factor subyacente de los principales rasgos del desequilibrio regional"12.

Me apresuraré a señalar que, junto a este análisis básico —e interrelacionadamente con él-se sitúan, obviamente, los componentes socio-políticos e institucionales, así como étnicos y culturales, en términos de actores sociales con proyectos y demandas diversas, que hacen al problema de la dinámica social y regional, en su conjunto.

Adicionalmente, debe resaltarse la notable insuficiencia de los tradicionales planteamientos y mecanismos básicos de la planificación global y sectorial, en el tratamiento de los problemas regionales, deficiencia esencialmente debida al supuesto de homogeneidad incluído en los enfoques e instrumentos habituales de la misma, lo que le lleva a la imposibilidad de captar las diferencias existentes en el plano real, tanto respecto al nivel regional como en cuanto a la distribución desigual de los niveles de ingreso personal.

Por cierto que esto mismo debe ser aplicado, en esta estrategia alternativa que se delinea, al análisis y atención consiguientes de las considerables diferencias existentes al interior mismo de las diversas comarcas andaluzas.

Abandonado pues, plenamente, el enfoque neoclásico como referencia teórica, instrumental y de política económica, conviene también distanciarse relativamente del enfoque desarrollista e industrialista, ya que éste, si bien plantea acertadamente que las disparidades regionales resultan de diferencias en la estructura productiva (esencialmente en cuanto a la presencia de actividades motrices o dinámicas, generalmente industriales), sigue considerando a la región como un todo homogéneo, y al ingreso per cápita como instrumento de medición de las disparidades regionales.

11. Para una exposición más detenida del enfoque metodológico de este análisis estructural de la economía mundial véase: Las economías capitalistas durante el período de expansión, 1945-1970. Estructura y funcionamiento del modelo de acumulación de posguerra, Enrique PALAZUELOS (coordinador), Pedro TALAVERA, Francisco ALBURQUERQUE, Fernando LUENGO y José DENIZ, Ed. AKAL, Madrid, 1986.

12. Stuart HOLLAND: op. cit., pág. 6. 
En el enfoque alternativo que se postula en este informe, las disparidades no se conciben entre regiones, sino como disparidades sociales, provocadas por la división territorial del trabajo y la organización social de la producción, así como el grado de concentración de la propiedad.

Las técnicas de análisis regional a utilizar, se refieren en este caso a los indicadores de concentración económica y de desigualdad social, tanto entre regiones como intrarregionalmente; así como a la matriz intersectorial o tabla de insumoproducto regional; y al análisis del circuito de los productos que conforman la base económica regional, y que nos permite vislumbrar el grado en que se retiene internamente el excedente económico ${ }^{13}$.

Por último, en cuanto a las recomendaciones de política alineadas con este enfoque alternativo, se encuentran todas aquellas medidas de política económica que incidan sobre la organización social de la producción, la distribución de la riqueza, y la apropiación y uso del excedente; así como las políticas administrativas que tiendan a modificar la correlación de fuerzas de los actores sociales.

En síntesis, la problemática regional en Andalucía está relacionada esencialmente - aunque no exhaustivamente - con los siguientes aspectos básicos:

1) La necesidad de impulsar el crecimiento económico, social y cultural de la región, atendiendo al muy elevado nivel de desempleo y marginalidad social en la misma, así como a la distribución desigual del ingreso, a nivel personal y comarcal.

2) La relativa incapacidad para impulsar el crecimiento económico autosostenido, debido al escaso grado de articulación productiva y la excesiva especialización regional en sectores poco dinamizadores, con limitados efectos difusores hacia el resto de la economía regional.

3) La excesiva concentración económica territorial (tipo enclave) de una industrialización esencialmente exógena, en el triángulo Huelva-SevillaCádiz, de Andalucía Occidental).

4) El elevado nivel de degradación de recursos naturales y ambientales, resultado de la instalación en la región de enclaves industriales profundamente contaminantes, que las regiones centrales desplazaron a otras periféricas, evitando así en ellas los riesgos y deseconomías correspondientes ${ }^{14}$.

13. Sobre técnicas de análisis regional con información limitada, puede verse el número 27 de Cuadernos ILPES, escrito por Sergio BOISIER, Santiago de Chile, 1980.

14. Por citar tan solo dos ejemplos, el "polo" industrial de Huelva, en la costa atlántica andaluza, es considerado acaso como uno de los mayores desastres ecológicos del reciente "desarrollismo" de los años sesenta en el Estado español, que amenaza incluso, en dicha zona, la importante reserva ecológica de las marismas del Parque de Doñana; y el principal vertedero de resíduos nucleares del Estado español está situado en un pueblo de Andalucía, en Hornachuelos (Córdoba). 
5) Las relativas insuficiencias y disfuncionalidades de las redes de transportes y comunicaciones regionales respecto a un modelo de crecimiento autocentrado; así como la desigual distribución de la población en los asentamientos urbanos y rurales, hecho éste relacionado en buena parte con la explotación intensiva del fenómeno turístico, que añade un poderoso componente de extranjerización cultural en la región, y no pocos deterioros ecológicos, ciertamente.

6) La desnacionalización cultural ligada a la importación de pautas de consumo foráneas, y a la interiorización de concepciones ideológicas extrañas, muy funcionales sin embargo, al estilo de vida ligado a los grandes negocios monopólicos transnacionales, que no aseguran, desde luego, un mayor bienestar humano y social, y que conllevan generalmente un desaprovechamiento de recursos propios regionales, junto a un incremento de importaciones y la consiguiente salida de divisas, como resultado de los "efectos de demostración" culturales, que penetran a través de los poderosos medios de comunicación de masas (principalmente, la televisión), conformando un patrón de consumo imitativo, disfuncional a la dotación de recursos propios y culturalmente ajeno.

7) La excesiva centralización del poder decisional relativo a parcelas estratégicas, lo que se ha agudizado con la reciente integración del Estado español a la Comunidad Europea, lo que implica de hecho, un "vaciado" de parte de las transferencias efectuadas desde el Estado central a las Autonomías, y que ahora se "trasladan" a Bruselas, donde no existe representación directa de la región, siendo asumida tal representación por el propio gobierno del Estado central.

\section{PROPOSITOS BASICOS Y ESTRATEGIA NACIONAL DE DESARROLLO REGIONAL PARA ANDALUCIA}

De lo anterior puede deducirse que los propósitos fundamentales en materia de desarrollo regional para Andalucía, en nuestra opinión, deben priorizar la atención a las necesidades básicas de los grupos más desfavorecidos, tratando de incrementar el grado de presencia y organización de estos grupos sociales, y relacionando todo ello con el objetivo básico de dotar a la región de una estructura productiva interna integrada capaz de incrementar el grado de aprovechamiento de los recursos propios. 
Ello quiere decir que no se confunde el propósito último en materia de desarrollo regional, que no es otro que la mejoría de las condiciones de vida de la población de menores ingresos, con aquel otro que se limita exclusivamente a intentar una relativa igualación regional de ingresos como objetivo de política económica, lo que no garantiza, en absoluto, aquel propósito citado como básico ${ }^{15}$.

Tal como señalan A.G. GILBERT y D.E. GOODMAN en el artículo citado, los programas regionales deben contener medidas que se dirijan a mejorar las oportunidades de los más desfavorecidos, extendiendo la cobertura de los servicios sociales, incrementando su acceso al empleo, y reduciendo las desigualdades de ingresos.

Es poco probable que ello se consiga con programas regionales orientados hacia la eficacia y basados en los hipotéticos efectos de "derrame" del crecimiento económico cuantitativo.

Asimismo es poco probable que disminuyan las desigualdades, a menos que los gobiernos adopten programas audaces de desarrollo regional, aunque ello - como ya se ha insistido suficientmenete-, dependerá del sistema político en cuestión y del poder de la representación regional en la política a nivel de Estado.

En materia de desarrollo regional -y, por cierto, también en cuanto a una estrategia de desarrollo global-, no debe privilegiarse tan simplistamente como objetivo básico (tal como suele hacerse en los enfoques neoclásico y desarrollista-industrialista) el logro del mayor ritmo de crecimiento económico, como si se tratase de una condición suficiente para alcanzar el desarrollo. En realidad, el desarrollo regional requiere una estrategia y objetivos encaminados a dotar al tejido productivo interno de la mayor cohesión o coherencia, con objeto de retener efectivamente el máximo del excedente económico generado en la región.

El crecimiento económico debe ser, pues, resultado de una estrategia encaminada hacia el logro de una mayor diversificación productiva interna, y no un fin -fetichizado- en sí mismo.

El desarrollo regional implica también, como se ha insistido, una creciente inclusión social, tanto en la apropiación del resultado de la actividad económica como en los procesos típicamente políticos ${ }^{16}$, lo que conduce a definir a la región como actor social del proceso de planificación frente al Estado, razón básica por la que este informe se plantea ante las instituciones propias de nuestro país andaluz, y no ante el gobierno del Estado.

15. Para una crítica del uso del criterio de igualación regional de ingresos como objetivo central de la planificación del desarrollo, y su compatibilidad o no con las estrategias orientadas a mejorar la distribución personal de ingresos, véase A.G. GILBERT y D.E. GOODMAN: "Desigualdades regionales de ingreso y desarrollo económico: un enfoque crítico". Revista Latinoamericana de Estudios Urbano-Regionales (EURE), número 13, Santiago de Chile, junio de 1976.

16. Sergio BOISIER, op. cit. Vid. Prefacio. 
La planificación participativa y estratégica de desarrollo regional que se busca, precisa pues del incremento de la capacidad de "negociación" y de presión ante el Estado, aumentando la incorporación de los actores sociales regionales (municipios, comarcas, entidades locales, asociaciones vecinales, organizaciones no gubernamentales, etc.), con objeto de actuar sobre la asignación de recursos interregional, así como sobre los efectos negativos de las políticas macroeconómicas y sectoriales, y sobre la movilización del potencial endógeno de recursos productivos no aprovechados suficientemente en la región.

Esto quiere decir: 1) Que se considera la planificación del desarrollo regional

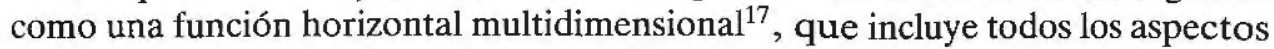
sustantivos relevantes (económico, ecológico, técnico y espacial por lado; y político-social, por otro), y que - por tanto- ha de tener entidad propia, definida desde la propia región, no limitándose únicamente a ser una planificación económica global a escala geográfica reducida; y 2) asímismo, que se descarta la consideración de la planificación del desarrollo regional como un instrumento autocontenido de la administración regional, orientándose por el contrario, y esencialmente, a viabilizar y maximizar la capacidad de intervenir en lo que BOISIER ha llamado el "entorno paramétrico", esto es, las condiciones, acontecimientos y decisiones externas a la región, que normalmente son más importantes que los propios elementos internos ${ }^{18}$. Ahora bien, si paralelamente a ello no se generan las bases de sustentación - tanto económicas como políticas o sociales_ del propio poder regional andaluz, poco o nada se habrá conseguido.

Por supuesto, se descarta asimismo que el desarrollo regional para Andalucía dependa exclusivamente de las políticas compensatorias o de los recursos financieros a transferir a la región, que no conllevan las necesarias transformaciones estructurales tendentes a dotar a la economía local de una mayor integración productiva sectorial, y con ello, un verdadero potencial de desarrollo endógeno y autosostenido.

La maximización de la capacidad de negociación regional exige crear o potenciar agentes empresariales y sociales locales, relacionados con la movilización de este potencial endógeno y recursos propios, ya que -en mi opinión-ambos aspectos están totalmente interrelacionados.

Esto último nos obliga a referirnos al papel de las burguesías locales en relación con la estrategia de desarrollo regional. En ningún caso se comparte la opinión -bastante corriente en el lenguaje e interpretaciones más vulgares- de que la falta de desarrollo regional se deba a la carencia de empresarios capaces

17. Idem., págs. 28-29.

18. Idem., pág. 93. 
en Andalucía. Dicha afirmación parece olvidar que los empresarios locales fueron lo suficientemente capaces para alcanzar a situarse en las líneas de producción o de intermediación, servicios, etc., que les permitían las mayores ganancias posibles con el menor riesgo. El que ello no llevara consigo el dinamismo económico suficiente para provocar efectos de difusión sobre la economía y sociedad locales, permitiría afirmar únicamente que la estructura económica interna subdesarrollada, en la que obtienen sus beneficios tales agentes empresariales, posee una lógica de reproducción diferente de la correspondiente a la estructura articulada y diversificada propia de las regiones o países centrales. Pero no que los empresarios sean en estos países más capaces, o emprendedores — subjetivamente-que en los países subdesarrollados.

Los empresarios andaluces que impulsaron el primer brote de la industrialización siderúrgica en España durante el siglo XIX, en Marbella (Málaga), no fracasaron por ser menos emprendedores, sino porque el carbón asturiano y el hierro del País Vasco se extraían a menor coste ${ }^{19}$.

Así pues, no sería, en efecto, la falta de empresarios, sino la existencia de fuertes condicionantes por el nivel de oligopolización económica transnacional y transregional existentes, lo que explicaría en gran medida las limitaciones y dificultades del desarrollo regional en la actualidad.

Lo que sí puede afirmarse es que falta en la región una estrategia de planificación del desarrollo regional que, consciente de estas limitaciones y condicinamientos, y con la información suficiente de cómo se concretan en ella las actuaciones de las distintas firmas sectoriales y su incidencia comarcal o territorial, establezca las líneas posibles y reales de actuación, respaldando o acompañando asimismo tal estrategia de desarrollo regional con la necesaria información previa de mercados, soporte de investigación para el desarrollo $(I+D)$, diseño de productos, financiación y comercialización adecuadas, marketing, capacidad gerencial y organización empresarial, etc. ${ }^{20}$.

Podría señalarse, acaso, que todos estos aspectos constituyen funciones del "empresario innovador" que se hecha en falta, pero no creo que sea ese el sentido en el que se efectúa vulgarmente la afirmación que relaciona el subdesarrollo con la falta de empresarios capaces.

Más que falta de empresarios capaces, estoy convencido de que quizás lo que sobran son bastantes dirigentes y responsables políticos y económicos mediocres, ignorantes, y ciertamente incapaces.

19. En 1826 se fundó en Málaga la empresa ferretera "La Concepción", impulsada por M.A. HEREDIA, que logró convertirse, entre 1833 y 1840, en el más importante industrial siderúrgico en España. (Vid. Jordi NADAL: El fracaso de la industrialización en España, Ed. Ariel, 1972).

20. Sobre esta cuestión creo que es del mayor interés lo aludido por Sergio BOISIER acerca de las "agrupaciones empresariales regionales" (vid. Cuadernos ILPES, n. ${ }^{\circ} 29$, cit. , págs. 115-116). 
Por lo demás, todas aquellas funciones empresariales, para que puedan alcanzar el éxito, requieren -y hoy más que nunca - de una adecuada colaboración e interpretación entre los distintos agentes empresariales privados y los poderes públicos ${ }^{21}$. En tal sentido se afirma la necesidad ineludible de un reparto del poder político entre regiones, lo que nunca será resultado de una entrega del Estado centralista y deberá ser, en todo caso, una conquista que habrán de arrancar los propios actores sociales y políticos regionales.

La estrategia de desarrollo regional que se sustenta es consciente de que se sitúa en un contexto complejo y difícil, que debe encarar también el poder de las grandes empresas y los grupos de presión extraterritoriales, esto es -y principalmente- de otras regiones centrales del Estado español, así como empresas transnacionales e internacionales situadas en Andalucía, cuya finalidad es el máximo lucro en los negocios o el predominio en el mercado local, lo que no es siempre compatible con el mayor desarrollo regional interno, y en ocasiones, lo impiden, objetivamente.

Se trata, en todo caso, y ante la irrealidad de plantearse, hoy por hoy, un escenario más óptimo (como sería el de una planificación orientada hacia la atención de las necesidades reales de todo el conjunto de la población, comenzando por las personas más necesitadas, e intentando potenciar las capacidades humanas en el sentido de la mayor justicia, libertad y solidaridad), de intentar forzar márgenes de acción posibles en el "estilo de desarrollo", explorando nuevas formas de organización social de la producción, como manera de generar e impulsar las iniciativas empresariales locales, procurando de este modo una planificación innovadora, democrática y participativa, y no solo una mera gestión de la misma dinámica de expansión desigual del sistema capitalista actual.

La estrategia de desarrollo regional para Andalucía no solo debe poseer un grado adecuado de eficacia técnica intrínseca, sino que debe mostrar asimismo un nivel de funcionalidad "técnica" y "política" 22 respecto a los objetivos económicos globales, siempre que éstos se orienten efectivamente hacia una articulación solidaria del Estado de las Autonomías.

Y asimismo, dicha estrategia debe superar un enfoque excesivamente limitado respecto a la problemática medio ambiental o ecológica, que tiende a reducirse frecuentemente a una mera cuestión de "gestión del medio".

21. Pese a la ideología contraria hoy predominante, lo cierto es que la casi totalidad de las experiencias con éxito industrializador en los países hoy desarrollados (quizá con la excepción de los EE.UU. de Norteamérica) se han apoyado en una poderosa intervención y proteccionismo inicial del Estado.

22. Sergio BOISIER: Diseño de planes regionales. Métodos y Técnicas de Planificación Regional, Colegio de Ingenieros de Caminos, Canales y Puertos, Madrid, 1976, pág. 27. 
Un compromiso ecológico en la estrategia de desarrollo regional y global implica la obligada inserción del medio ambiente natural y energético como factores o variables básicas fundamentales en el propio diseño decisional de las diversas alternativas, modalidades o estilos de desarrollo; lo que es ciertamente distinto a la simple consideración "ex-post" de los efectos resultantes del proceso de crecimiento.

Ello obliga a valorar las distintas combinaciones factoriales productivas "exante", así como sus efectos consiguientes en relación con la destrucción que conllevan en el medio natural (y sobre todo, en relación con el uso y explotación de los recursos naturales no renovables), lo que, además, no puede medirse exclusivamente en puros términos monetarios, debiendo efectuarse básicamente la medición en términos de los correspondientes balances energéticos ${ }^{23}$.

Nos quedaría explicitar, adicionalmente, nuestro acuerdo en una estrategia de tipo combinado, que sepa utilizar centros de crecimiento dinámico, siempre que ellos sean efectivamente capaces de articular paulatinamente todo el tejido productivo regional andaluz, rescatándose de este modo el sentido interpretativo de la aportación pionera de PERROUX ${ }^{24} \mathrm{y}$, por cierto, también la muy importante de J.A. SCHUMPETER que, en definitiva, desarrollan un conocimiento mayor acerca de la lógica de funcionamiento de la acumulación capitalista, lo cual, tal como he insistido, constituye una exigencia obligada.

Parece, por lo demás, bastante inobjetable reconocer la necesidad de:

1) La utilización eficiente del capital.

2) El aprovechamiento de economías externas.

3) La concesión de prioridades al sector industrial manufacturador de los recursos propios en la propia región, y relacionadamente con ello, la generación o introducción de tecnologías adaptadas a esos procesos.

4) El activo papel del sector público - tanto regional como estatal- en cuanto a la provisión de infraestructura física, capital bumano, financiación, I+D, etc.

23. Es este un tema del mayor interés, que constituye, como es sabido, un elemento de referencia principal en los movimientos alternativos ecologistas, y que se alinean asimismo, y de forma decidida en sus formulaciones más conscientes, a favor de estrategias alternativas de "otro" desarrollo, comprometido con la atención prioritaria de las necesidades básicas de la inmensa mayoría de la humanidad, y no con el estilo degradante del crecimiento industrialista y consumista predominantes.

24. Vid.: Los polos de crecimiento: la teoría y la práctica en América Latina, ILPES, Temas de Planificación, Dos volúmenes, Santiago de Chile, 1977. 
Al insistir, no obstante, en una estrategia "de tipo combinado", queremos decir que se opta por una combinación de la estrategia de crecimiento polarizado multipuntual (que intenta establecer una red de relaciones interindustriales y agroindustriales, junto a un sistema de ciudades, o_- en otras palabras - una matriz completa de actividades y ciudades), y la estrategia de crecimiento no polarizado, con diseminación más extensa de actividades, proyectos de desarrollo rural integrado (DRI) para comarcas pobres y de agricultura de alta montaña, creación de ciudades de tamaño intermedio y sistema interior de comunicaciones, impulso de pequeñas y medianas empresas (PYMES), relacionadas - sobre todocon el procesamiento de los recursos naturales y productos alimenticios, y orientadas hacia la atención de las necesidades básicas de la población, etc.

\section{IMPLEMENTACION DE LA ESTRATEGIA PROPUESTA Y FACTIBILIDAD SOCIAL Y POLITICA}

Una tarea importnte para la implementación de la estrategia de desarrollo regional es la disposición de un Instituto de Investigación, Análisis e Información, suficientemente capaz de diagnosticar y prever la coyuntura global y sectorial de la situación socio-económica regional y comarcal andaluza, así como del contexto enterno condicionante: economía y política económica y social a nivel estatal, de la CEE, e internacional.

Para esto es absolutamente prioritario el mejoramiento -e incluso ampliación- de las estadísticas regionales y estatales, así como de las diversas técnicas de análisis y procedimientos que faciliten la mejor comprensión del tejido productivo y social de nuestra Comunidad Autónoma, llegando - lógicamente- - a los planos municipal, comarcal y local.

Entre las tareas inmediatas de este Instituto se encontrarían la elaboración exhaustiva del inventario de recursos productivos y tecnológicos, reales y potenciales, de Andalucía; lo que debe efectuarse, en todo caso, con la participación activa de todos los actores socio-económicos interesados o implicados.

Como es obvio, esto conlleva la exigencia de una administración regional lo suficientemente flexible y ágil, para ser capaz de adaptarse a tales procedimientos participativos, lo que puede considerarse como una tarea difícil, pero no imposible. Ello podría facilitarse progresivamente, a través de la adecuada formación y capacitación de expertos regionales, en todas las facetas - técnicas y administrativas - que requiere esta planificación estratégica e innovadora; lo que implica, entre otras consideracones, que el sistema educativo y el científico-tecnológico deban adecuarse y orientarse a la búsqueda de soluciones a los problemas planteados en la sociedad regional, y no a otra consideración, o a la inversa. 
En todo caso, es importante diferenciar las tareas de investigación, análisis e información, de aquellas otras relativas a las líneas específicas de actuación en proyectos y programas concretos, que constituyen el campo concreto de los expertos planificadores y de los promotores y gerentes de las actividades que se alienten.

Para estas líneas de actuación, la Consejería de Desarrollo Regional deberá contar con un Organismo de Promoción Económica Regional (que debe ocuparse tanto de la promoción industrial en Andalucía, como de lo relativo a la reforma agraria y el desarrollo rural integrado), y que debe tener presencia activa en todas las comarcas, así como estar estrechamente conectado con las entidades de base que aglutinan y organizan a los diversos actores sociales locales, esto es, alcaldías, agrupaciones empresariales, sindicatos obreros y campesinos, cámaras de comercio, asociaciones vecinales, movimientos sociales, universidades y centros de formación profesional, banca local y cajas de ahorro, etc., con objeto de actuar como dinamizadores y coordinadores de los proyectos comarcales o sectoriales que se redefinan o se impulsen, según líneas de rentabilidad y viabilidad técnica, social y financiera.

Los organismos citados facilitarían el acceso a la capacitación gerencial y empresarial de las iniciativas surgidas, y dotarían a las mismas de la suficiente información de mercados, tecnologías, diseño, lineas de comercialización y financiación, etc., procurándoles asimismo la simplificación de las tramitaciones de orden burocrático en sus relaciones con las distintas entidades de la Junta de Andalucía.

Asímismo, una Sociedad para la Financiación del Desarrollo Regional en Andalucía, de carácter público, podrá promover líneas especiales de financiación a proyectos mixtos, participar como co-propietaria de empresas regionales, facilitar los avales a empresarios pequeños y medianos, etc.

Por supuesto, las empresas públicas regionales, así como las empresas estatales localizadas en Andalucía, deberán orientar sus actividades según los lineamientos de la planificación del desarrollo regional de Andalucía.

En relación con los efectos indirectos desiguales que provocan las políticas macroeconómicas y sectoriales, es preciso incrementar al máximo el poder de negociación ante el Estado central, con el fin de intentar incorporar la dimensión regional en el análisis del funcionamiento del sistema económico y en el proceso de formulación de políticas. Se debe insistir, en efecto, en que una discriminación espacial de tales políticas puede permitir una mayor eficiencia en la asignación global de los recursos y una mayor productividad de las inversiones, lo que implica - por tanto- aumentar la capacidad de regulación del sistema económico. 
Como cuestión fundamental, deben tratar de evitarse las continuas transferencias de ahorro que, bien a través de dicha aplicación indiscriminada de políticas macro o sectoriales, o bien a través de otros procedimientos, operan permanentemente en contra de la región, deteriorando los términos de intercambio interregionales, e impidiendo la plena utilización del excedente económico generado internamente.

Si bien frente a este tipo de políticas estatales apenas cabe, a veces, otra cosa que mantener activa la capacidad de negociación y presión regional, no es éste el caso de otras políticas públicas que pueden implementarse desde el gobierno autonómico o desde las instancias municipales. Es ahí donde deben forzarse al máximo los márgenes de maniobra del peculiar estilo de desarrollo, impulsando y favoreciendo el potencial endógeno regional: actividades ligadas a la explotación de recursos propios; ampliación de los procesos de manufacturación en la propia región; organización de productores regionales, incluyendo canales de comercialización propios; promoción de PYMES orientadas hacia el mercado interno; etc.; acompañando todo ello con la creación de "externalidades positivas", esto es, infraestructura e incentivos, desde el Sector Público Regional y Municipal.

En cuanto a las políticas de medio ambiente, deben plantearse las acciones necesarias para impedir las deseconomías derivadas de la excesiva concentración o aglomeración de actividades, procurando alcanzar escalas y técnicas de producción que combinen los niveles de eficacia con la necesaria reproducción del medio ambiente natural, lo que es plenamente compatible con una mayor utilización de mano de obra, y una distribución más difundida en el territorio de la planta productiva y los asentamientos humanos.

Es precisamente la constatación de la interrelación existente entre lo "urbano" y lo "rural" lo que obliga a considerar ambos fenómenos de competencia de la Consejería de Desarrollo Regional, a la que deben encontrarse vinculados y conectados los organismos específicos que tengan competencias relacionadas con aquellos aspectos, esto es, Obras Públicas, Vivienda y Urbanismo, Transportes y Comunicaciones —entre otros_, de un lado; y Agricultura, Extensión Agraria, u otros Servicios Rurales, etc., de otro.

La problemática regional no solo es "urbana", ya que cualquier sistema de ciudades y actividades industriales o agroindustriales se encuentra relacionado con el grado de eficacia con que las actividades primarias, el medio ambiente y el sector rural, permiten los abastecimientos básicos energéticos, de materias primas, productos alimenticios, y otros.

Se hace necesario, por tanto, contrapesar el excesivo sesgo gigantista-urbanizador que ha acompañado al industrialismo, tratando de dotar a los asentamientos rurales de todos los servicios técnicos, educativos, sociales, culturales, asistenciales, etc., de modo que no se den las enormes diferencias, tan desfavorables para los habitantes de pequeñas poblaciones campesinas, respecto a los habitantes de las grandes ciudades. 
La organización espacial rural, basada en un sistema de concentración de poblaciones rurales, adecuadamente integrado por redes de transportes y comunicaciones, constituye, en efecto, una tarea que debe ser encarada, y que se encuentra - a su vez - vinculada a una industrialización de estos núcleos urbanos de tamaño intermedio, o en otras palabras, que implica una desconcentración espacial de la industria ${ }^{25}$.

Finalmente, es preciso recordar que la crisis económica internacional constituye, realmente, la quiebra del modelo de acumulación capitalista central de postguerra, hecho éste en el que, de manera determinante, han influido diversos factores:

1) La profunda renovación tecnológica e industrial sectorial ligada a los incrementos continuos del nivel de competitividad en los mercados, cada vez más oligopólicos, con la correspondiente sustitución de actividades y sectores líderes o dinamizadores de dicho modelo de acumulación; lo que ha provocado, lógicamente, el declive de otras industrias y sectores que anteriormente lideraban el proceso de la acumulación.

2) La profundización de la denominada "nueva división internacional del trabajo" o deslocalización transnacional de la actividad productiva a nivel espacial, provocando el declive de determinadas áreas geográficas.

3) La incertidumbre establecida respecto al abastecimiento energético, tras el cierre de la época de petróleo barato, y la dificultad para hacer operativa la alternativa nuclear, en un contexto adicional de alta contestación social de la misma.

4) El agotamiento relativo del ritmo de demanda de productos de consumo duradero, dada la persistencia de la muy desigual distribución personal del ingreso.

5) La desarticulación monetaria y financiera internacional, ante la creciente autonomía de las fracciones financieras del capital en la época actual, junto a la inestabilidad potencial de dicho sistema monetario internacional, profundamente desigual y asimétrico, que sigue basándose en la supremacía política del dolar norteamericano, pese a ser la economía norteamericana la más endeudada del mundo.

25. Sergio BOISIER, en Diseño..., op. cit., págs. 13-14. 
La distorsión especulativa e improductiva que se da hoy en el escenario internacional como consecuencia de todo este panorama, ayuda a comprender tanto la ralentización del crecimiento económico actual como la tendencia de los capitales a buscar refugio en las esferas especulativa o financiera, a la espera de mejores o más claras perspectivas de ganancias extras en la inversión productiva o real.

En este contexto condicionante, la búsqueda de una estrategia más autónoma de desarrollo económico regional, que indague los elementos del potencial endógeno relacionado con la utilización de los recursos propios, parece absolutamente necesaria, frente al actual modelo "asociado" al estilo de desarrollo transnacional, esto es, frente al estilo de crecimiento que nos ha traido - precisamente- a la crisis actual.

La estrategia alternativa de desarrollo regional planificado, debe encarar, no obstante, la dificultad adicional de la internacionalización de la política económica monetarista, hecho éste que - liderado hoy por la actual administración norteamericana-, constituye acaso el más inmediato obstáculo al relanzamiento en mayor magnitud de las inversiones productivas para el crecimiento y el desarrollo económicos.

De ahí el desafío que comporta la crítica situación actual, con sus resultantes de lento crecimiento, fuerte exclusión social, altos niveles de desempleo y subempleo de la mano de obra (hecho éste que ya ha dejado de ser "exclusivo" del mundo subdesarrollado), aparición de las más diversas formas de economía informal y marginalidad, crisis fiscal del Estado y creciente endeudamiento, etc., que dificultan poderosamente la implementación de cualquier estrategia contra corriente del poder "mesoeconómico" transnacional y de las grandes potencias.

En síntesis, la necesaria acción social regional capaz de hacer posible la estrategia de desarrollo que se formula, se encuentra frente a los siguientes factores condicionantes ${ }^{26}$ :

a) La específica racionalidad del sistema socio-económico y del estilo de desarrollo predominantes.

b) La orientación y contenido del proyecto político y económico sustentado por el grupo social hegemónico actual (PSOE), notablemente subordinado a las directrices condicionantes de la actual política de la administración norteamericana ${ }^{27}$.

26. Carlos A. de MATTOS: "Paradigmas, modelos y estrategias en la práctica latinoamericana de planificación regional". ILPES. Documento CPRD D/88, págs. 25 y siguientes.

27. Ver mi ensayo: "La evolución histórica reciente de la planificación indicativa en el Estado español y el actual contexto general limitativo de la planificación regional del desarrollo". Mimeo. XXVII Curso Internacional ILPES. Mención de Planificación del Desarrollo Regional, Naciones Unidas, Santiago de Chile, 1986. 
c) La inexistencia de una estrategia propia de desarrollo regional por parte del actual gobierno autonómico (PSOE-Andalucía), plenamente subordinado a la dirección orgánica del partido en el gobierno central del Estado.

Frente a ello, la creciente conciencia regional, tanto respecto a los desequilibrios socio-económicos interregionales, como respecto al deterioro de las condiciones de vida y de la propia identidad étnica y cultural como pueblo ${ }^{28}$, acabarán por poner en pie las iniciativas, la organización y la movilización populares en los ámbitos regional y local, extensivamente, hasta el punto de mostrar la certeza de la afirmación de FRIEDMAN y WEAVER en el sentido de que, probablemente, este tipo de desarrollo regional alternativo que se pretende alcanzar, responda más a oportunidades históricas que a una planificación tecnocrática, o a la voluntad de los planificadores ${ }^{29}$.

$\mathrm{Y}$ aunque no siempre suele suceder así, los momentos de crisis son también aquellos en los que, organizadamente, los actores sociales se ven empujados a la necesaria búsqueda de caminos alternativos.

En esa búsqueda, el pueblo andaluz tiene aún pendiente la aspiración de libertad y autonomía nacional que refleja, por ejemplo, la letra de uno de nuestros cantes populares:

\author{
"Ni dioses, ni reyes, ni ná; \\ en mí mando yo solito, \\ y no manda nadie má".
}

28. Ver mi ensayo: "Notas sobre el etnoregionalismo andaluz y la importancia de los movimientos andalucistas en la estrategia alternativa de desarrollo regional". Mimeo. Seminario sobre Movimientos Sociales Regionales. XXVII Curso Internacional ILPES, Mención de Planificación del Desarrollo Regional, Naciones Unidas, Santiago de Chile, 1986.

29. J. FRIEDMAN y C. WEAVER: Territory and Function, Edward Arnold. Londres, 1979. Citado por José ABALOS, Documento ILPES CPRD-C/70, pág. 38. 